\title{
CRISPR/Cas9-induced $\beta$-carotene hydroxylase mutation in Dunaliella salina CCAP19/18
}

Lina $\mathrm{Hu}^{1+}$, Shuying Feng ${ }^{1,2^{*}+} \mathbb{D}$, Gaofeng Liang ${ }^{1}$, Jingxia $\mathrm{Du}^{1}$, Aifang $\mathrm{Li}^{3}$ and Chunling $\mathrm{Niu}^{2}$

\begin{abstract}
Dunaliella salina (D. salina) has been exploited as a novel expression system for the field of genetic engineering. However, owing to the low or inconsistent expression of target proteins, it has been greatly restricted to practical production of recombinant proteins. Since the accurate gene editing function of clustered regularly interspaced short palindromic repeat (CRISPR)/Cas system, $\beta$-carotene hydroxylase gene was chosen as an example to explore D. salina application with the purpose of improving expression level of foreign genes. In this paper, based on pKSE401 backbone, three CRISPR/Cas9 binary vectors were constructed to targeting exon 1 and 3 of the $\beta$-carotene hydroxylase of D. salina CCAP19/18 (Dschyb). D. salina mutants were obtained by salt gradient transformation method, and the expression of Dschyb gene were identified through real-time fluorescent quantitative PCR. Moreover, carotenoids content was analyzed by high-performance liquid chromatography at different time points after high intensity treatment. Compared with wild type strains, the $\beta$-carotene levels of mutants showed a significant increase, nearly up to $1.4 \mathrm{\mu g} / \mathrm{ml}$, and the levels of zeaxanthin decreased to various degrees in mutants. All the results provide a compelling evidence for targeted gene editing in $D$. salina. This study gave a first successful gene editing of $D$. salina which has a very important practical significance for increasing carotene yield and meeting realistic industry demand. Furthermore, it provides an approach to overcome the current obstacles of D. salina, and then gives a strong tool to facilitates the development and application of D. salina system.
\end{abstract}

Keywords: D. salina, CRISPR/Cas9, $\beta$-carotene hydroxylase, Knockout, Mutant

\section{Introduction}

Presently, Dunaliella salina (D. salina) is the best commercial source of natural $\beta$-carotene. According to the optimized condition, $\beta$-carotene could accumulate up to $32.0 \mathrm{mg} / \mathrm{L}$ (Xi et al. 2020). And now, D. salina has been used as a huge commercial sources of carotenoids, such as phytoene, phytofluene, lutein, and zeaxanthin (Xu et al. 2018; Saha et al. 2018; Liang et al. 2019). Not only that, the raising market demand for natural pigments increased the efforts to enhance production of

\footnotetext{
*Correspondence: fshy001@haust.edu.cn

${ }^{\dagger}$ Lina Hu and Shuying Feng contributed equally to this work

1 School of Basic Medical Sciences, Henan University of Science

and Technology, No. 263 Kaiyuan Avenue, Luoyang 471023, Henan, China

Full list of author information is available at the end of the article
}

carotenoids from biological sources. Although several studies have addressed the effect of different culture conditions on $\beta$-carotene content in D. salina, its accumulation leads to reduced growth rates, including extreme temperatures, high salinity, and nitrogen limitation $(\mathrm{Xu}$ and Harvey 2019). So, molecular approaches have shown great potentials to enhance the accumulation of bioproducts, such as metabolic engineering, transcriptional engineering, and gene disruption strategies (Wichuk et al. 2014; Zhang et al. 2018).

The clustered regularly interspaced short palindromic repeat (CRISPR) technology is a versatile tool to perform genome editing in different organisms ranging from prokaryote to eucaryote. And now, CRISPR/ Cas system has been used as an enormously powerful
Springer Open (c) The Author(s) 2021. This article is licensed under a Creative Commons Attribution 4.0 International License, which permits use, sharing, adaptation, distribution and reproduction in any medium or format, as long as you give appropriate credit to the original author(s) and the source, provide a link to the Creative Commons licence, and indicate if changes were made. The images or other third party material in this article are included in the article's Creative Commons licence, unless indicated otherwise in a credit line to the material. If material is not included in the article's Creative Commons licence and your intended use is not permitted by statutory regulation or exceeds the permitted use, you will need to obtain permission directly from the copyright holder. To view a copy of this licence, visit http://creativeco mmons.org/licenses/by/4.0/. 
tool in the drug discovery, disease treatment, pollution control, and other fields (Fellmann et al. 2017; Khadempar et al. 2019; Feng et al. 2020). Thus, this system offers an excellent integration point for development of D. salina bioreactor. Competent CRISPRbased genome editing techniques have been reported in several microalgal species, such as enhancing of lipid content, and improving of biomass production (Liang et al. 2019). Compare with the traditional transgenic methods, CRISPR/Cas system has advantages of easy design, high-efficiency, and capability of multiplex genome editing (Sternberg et al. 2014).

$\beta$-Carotene hydroxylase is a key enzyme in the pathway of carotenoid biosynthesis in plants, which catalyse the conversion of $\beta$-carotene to zeaxanthin for carotenoid biosynthetic pathway (Lamers et al. 2008). In theory, blocking or silencing this enzyme can increase the content of $\beta$-carotene in $D$. salina cells. For instance, RNA interference technology has been used to silence $\beta$-carotene hydroxylase of maize endosperm and potatoes, which successfully increased the carotene content (Berman et al. 2017; Kim et al. 2012). To test our hypothesis, we attempted to knockout $\beta$-carotene hydroxylase of $D$. salina (Dschyb) gene with CRISPR/Cas9 system. The results demonstrated that the specific-mutants of Dschyb have been successfully created by CRISPR technology. This is the first report of gene editing in D. salina with the CRISPR/ Cas system. It not only can facilitate the development and application of $D$. salina system, but also give a strong tool to overcome the current obstacles of $D$. salina.

\section{Materials and methods}

\section{Algal strain and culture conditions}

D. salina CCAP19/18 D Kessler were purchased from the Guangyu Biotech Co., Ltd (Wenzhou, China), and cultured in the modified PKS medium, which comprising $1.5 \mathrm{M} \mathrm{NaCl}, 10 \mathrm{mM} \mathrm{KNO} \mathrm{KN}_{3}, 50 \mathrm{mM}$ $\mathrm{NaHCO}_{3}, 5 \mathrm{mM} \mathrm{MgSO}{ }_{4} \cdot 7 \mathrm{H}_{2} \mathrm{O}, 0.4 \mathrm{mM} \mathrm{KH}_{2} \mathrm{PO}_{4}, 2 \mu \mathrm{M}$ $\mathrm{FeCl}_{3} \cdot 6 \mathrm{H}_{2} \mathrm{O}, 5 \mu \mathrm{M}$ EDTA, $7 \mu \mathrm{M} \mathrm{MnCl} \mathrm{Mn}_{2} \cdot 4 \mathrm{H}_{2} \mathrm{O}, 1 \mu \mathrm{M}$ $\mathrm{CuCl}_{2} \cdot 2 \mathrm{H}_{2} \mathrm{O}, 1 \mu \mathrm{M} \mathrm{ZnCl}, 1 \mu \mathrm{M} \mathrm{CoCl}_{2} \cdot 6 \mathrm{H}_{2} \mathrm{O}, 1 \mu \mathrm{M}$ $\left(\mathrm{NH}_{4}\right) \mathrm{Mo}_{7} \mathrm{O}_{24} \cdot 4 \mathrm{H}_{2} \mathrm{O}, 185 \mu \mathrm{M} \mathrm{H}_{3} \mathrm{Bo}_{3}, 0.2 \mathrm{mM} \mathrm{CaCl}_{2}$, at $26^{\circ} \mathrm{C}$ with a $12 \mathrm{~h}$-light/day under light intensity of 4000 Lux. The pKSE401 vector was a gift from Professor Gongyao Shi of Zhengzhou University. In previous studies, pKSE401 vector has been successfully applied into Arabidopsis (Xing et al. 2014) and Brassica napus (B. napus) (Yang et al. 2017) to generate mutants with a high efficiency. zCAS9-NLS was under control of two constitutive $35 \mathrm{~S}$ promoters, and the sgRNA scaffolds expression was driven by Arabidopsis U6-26 promoter.
Table 1 The primers used for different vectors construction

\begin{tabular}{lll}
\hline Primer name & Base sequence (5' $\mathbf{5}^{\prime}$ ) & Vector name \\
\hline sgRNA1-F & ATTGGGCTAACCCACTGACACCCA & pKSE401-sgRNA1 \\
sgRNA1-R & AAACTGGGTGTCAGTGGGTTAGCC & \\
sgRNA2-F & ATTGGATGCGGGTGAGATGCCTTG & pKSE401-sgRNA2 \\
sgRNA2-R & AAACCAAGGCATCTCACCCGCATC & \\
sgRNA3-F & ATTGTGCGCAACAACAGCTACAGG & pKSE401-sgRNA3 \\
sgRNA3-R & AAACCCTGTAGCTGTTGTTGCGCA & \\
\hline
\end{tabular}

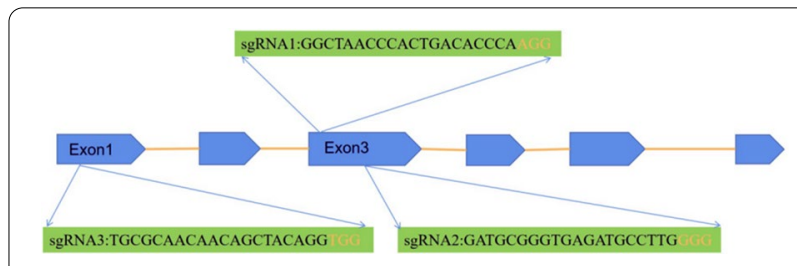

Fig. 1 Schematic diagram of three sgRNA targeting sites for Dschyb locus. Blue module represents exon; Orange line represents intron; Orange marked sequence is PAM site

\section{Vector construction and $D$. salina transformation}

We manually search for 23 bp target sites (5'-N 20 NGG3') within exons of genomic DNA sequences of Dschyb (GenBank: KX096216.1) on the website of http://crispr. dbcls.jp/. Based on the optimization principles (Nymark et al. 2016), three single guide RNA (sgRNA) sequences were designed to introduce two $B s a$ I flanking sites and named in sgRNA1-F, sgRNA2-F and sgRNA3-F, respectively (Table 1). Golden gate cloning was used to assemble sgRNA, which allows to obtain nearly one hundred percent correct recombinant plasmids (Vecchione et al. 2019). For assembly of sgRNA, equal volumes of $100 \mu \mathrm{M}$ oligos 1 and 2 were mixed and then incubated at $80^{\circ} \mathrm{C}$ for $10 \mathrm{~min}$. After that, the mixture was cooled slowly to room temperature, resulting in a double-stranded insert with 4-nt $5^{\prime}$ overhangs at both ends. Annealed doublestranded oligonucleotides together with pKSE401 was used to set up restriction-ligation reactions using $B s a$ I and T4 ligase (NEB, Ipswich, USA). The reaction was incubated orderly in a thermocycler for $2 \mathrm{~h}$ at $37^{\circ} \mathrm{C}, 5 \mathrm{~min}$ at $50^{\circ} \mathrm{C}$ and $10 \mathrm{~min}$ at $80^{\circ} \mathrm{C}$. Consequently, the constructed plasmids were named as pKSE401-sgRNA1, pKSE401sgRNA2 and pKSE401-sgRNA3, which correspond to the regions in exon 3 and 1 of Dschyb, respectively (Fig. 1). Using these constructed plasmids, $D$. salina cells were transformed separately with salt gradients method (Feng et al. 2020). After 2-3 days transformation, cells were cultured in fresh medium with $700 \mu \mathrm{g} / \mathrm{mL}$ G418 in a 12-well plate at $26^{\circ} \mathrm{C}$ light incubator. And then, transformed cells were plated on the solid antibiotic-free medium $(0.8 \%$ 
agarose, w/v) to obtain single colonies. During 10 days culture, culture dishes were inverted and placed in an illuminated incubator with $12 \mathrm{~h}$ light $/ 12 \mathrm{~h}$ dark $\left(26^{\circ} \mathrm{C}\right)$ photo-period. Finally, the positive colonies were detected by polymerase chain reaction (PCR) amplification and gene sequencing.

\section{PCR identification of mutants}

The single algae colonies were picked with a $10 \mu \mathrm{L}$ inoculation loops and re-suspended in fresh medium. Another portion of the same single colony was directly used for single algae colony PCR with the Phire Plant Direct PCR Master Mix kit (Thermo Fisher Scientific, Shanghai, China). Briefly, a $0.5 \mathrm{~mm}$ single algae colony was picked from the agar plate using a pipette. The samples were placed directly into $50 \mu \mathrm{L}$ PCR reactions. Reactions were run following the cycling conditions: $5 \mathrm{~min}$ at $98{ }^{\circ} \mathrm{C}$, then 35 cycles of $5 \mathrm{~s}$ at $98{ }^{\circ} \mathrm{C}, 5 \mathrm{~s}$ at $58.4{ }^{\circ} \mathrm{C}, 40 \mathrm{~s}$ at $72{ }^{\circ} \mathrm{C}$, and a final extension of $1 \mathrm{~min}$ at $72{ }^{\circ} \mathrm{C}$. The PCR products were analyzed by $1 \%$ agarose gel electrophoresis. Next, Mutants were screened by analyzing the size of PCR products. Sanger sequencing reactions of PCR products were carried out by Sangon Biotech Co., Ltd (Shanghai, China). Finally, DNA sequences were analyzed with the snapgene software.

\section{sgRNA transcription in vitro and cleavage assay}

Using pKSE401 as the template, forwards primers were designed for adding the T7 promoter sequence (TTA ATACGACTCACTATAGG) into sgRNA loop by PCR. T7 sgRNA-R-common was used as the reverse primer to obtain the final DNA fragment for transcription in vitro. PCR was carried out using $2 \mathrm{X}$ high fidelity PCR master mix (Sangon, Shanghai, China) as follows: initial denaturation at $95{ }^{\circ} \mathrm{C}$ for $30 \mathrm{~s}, 35$ cycles of $95{ }^{\circ} \mathrm{C}$ for $15 \mathrm{~s}, 58{ }^{\circ} \mathrm{C}$ for $15 \mathrm{~s}$ and $72{ }^{\circ} \mathrm{C}$ for $20 \mathrm{~s}$, a final extension at $72{ }^{\circ} \mathrm{C}$ for $5 \mathrm{~min}$, and termination at $4{ }^{\circ} \mathrm{C}$. The T7-sgRNA primer sequence are summarized in Table 2, which named T7-sgRNAF1, T7-sgRNA-F2, and T7-sgRNA-F3, respectively. The corresponding DNA were transcribed in vitro with the HiScribe T7 high yield RNA synthesis kit (NEB, Ipswich, USA). Next, sgRNAs (T7-sgRNA1, T7-sgRNA2 and T7-sgRNA3) for targeting Dschyb were produced with the transcriptions in vitro.

Before cleavage assay, total RNAs were purified using Trizol (Cwbio, Taizhou, China) and finally dissolved in RNase free water. Purified RNA was quantified by spectrometry for further use. To obtain the RNP complex harbouring pre-assembled Cas effector protein and the targeting sgRNA, equimolar amount of Cas protein (YSY, NanJing, China) and sgRNA were incubated in a sterile $1.5 \mathrm{~mL}$ eppendorf tube at $37{ }^{\circ} \mathrm{C}$ for $15 \mathrm{~min}$ along with $3 \mu \mathrm{L} 10 \mathrm{X}$ Cas buffer and milliQ water to a final volume of $30 \mu \mathrm{L}$. After 15 min incubation, $400 \mathrm{ng}$ of target DNA was added into the reaction mixture and incubated again for $1 \mathrm{~h}$. And then, Cas9 nuclease was inactivated at $65{ }^{\circ} \mathrm{C}$ for $10 \mathrm{~min}$. The target DNA was amplified from the host genomic DNA with the high fidelity PCR master mix (Sangon, Shanghai, China) using primers CHY-F and CHY-R (Table 2). After that, PCR fragments were analyzed by $1 \%$ agarose gel electrophoresis. Simultaneously, this assay was performed with individual ribonucleoprotein (RNP) complex or with different duplex combinations.

\section{Comparison of $\beta$-carotene hydroxylase level in D. salina and its pigment analysis}

Usually, carotenoids accumulated with increasing light emitting diode (LED) light intensity. So, Cells were grown under 12/12 light/dark (L/D) with $4000 \mathrm{Lux} \mathrm{m}^{-2} \mathrm{~s}^{-1}$ supplied by LED light to exponential growth phase and then exposed continuously to $6000 \mathrm{Lux} \mathrm{m}^{-2} \mathrm{~s}^{-1} \mathrm{LED}$ light. After further growth for $24 \mathrm{~h}$ in white LED light, cultures were used to monitor the changes in the Dschyb mRNA levels and cellular carotenoids. After that, expression levels of Dschyb in different strains were examined by real-time fluorescent quantitative PCR (RT-qPCR). RT-qPCR reaction was conducted in 96-well plates

Table 2 The primers used for sgRNA transcription in vitro and target genes

\begin{tabular}{|c|c|c|}
\hline Primer name & Base sequence $\left(5^{\prime}-3^{\prime}\right)$ & Purpose \\
\hline T7-sgRNA-F1 & $\begin{array}{l}\text { TTAATACGACTCACTATAGGCTAACCCACT } \\
\text { GACACCCAGTTTTAGAGCTAGAAATAGC }\end{array}$ & Transcription in vitro \\
\hline T7-sgRNA-F2 & $\begin{array}{l}\text { TTAATACGACTCACTATAGGATGCGGGTGA } \\
\text { GATGCCTTGGTTTTAGAGCTAGAAATAGC }\end{array}$ & Transcription in vitro \\
\hline T7-sgRNA-F3 & $\begin{array}{l}\text { TTAATACGACTCACTATAGGTGCGCAACAA } \\
\text { CAGCTACAGGGTTTTAGAGCTAGAAATAGC }\end{array}$ & Transcription in vitro \\
\hline T7 sgRNA-R-common & AAAAGCACCGACTCGGTGCC & Transcription in vitro, colony PCR \\
\hline $\mathrm{CHY}-\mathrm{F}$ & AAGGTCAACACAAGGGAACGA & Target gene Dschyb \\
\hline CHY-R & GTTTGGTGTCAGGAAGCCGT & \\
\hline
\end{tabular}


Table 3 The primers for RT-qPCR

\begin{tabular}{lll}
\hline Primer name & Base sequence (5'-3') $^{\prime}$ & Purpose \\
\hline B-CHY-F & GGAGCAGCAATTTTACAAGC & Dschyb RT-qPCR \\
B-CHY-R & CACTCCTCCAGCCACAAG & \\
$\beta$-actin-F & CGACCGCATGAGCAAAGAGA & $\beta$-actin RT-qPCR \\
$\beta$-actin-R & CGCTCTCGTCGTACTCTGAC & \\
\hline
\end{tabular}

containing cDNA template and gene specific primers (Table 3). At the same time, the housekeeping gene $\beta$-actin was used as an internal standard. Total RNA and cDNA amounts were determined with the NanoDrop One spectrophotometer (Thermo Scientific, Madison, USA). Subsequently, gene expression level was calculated by $2^{-\Delta \Delta C t}$ method with ABI 7500 manager program. On the other hand, biomass was harvested and extracted for high-performance liquid chromatography (HPLC) analysis as described by $\mathrm{Xu}$ et al. with slight modification (Xu and Harvey 2019). Using a Hypersil GOLD ${ }^{\mathrm{TM}} \mathrm{C}-18$ reverse phase $(250 \times 4.6 \mathrm{~mm}, 5 \mu \mathrm{m}$ particle size $)$ HPLC column (Thermo Scientific,Waltham, USA), $\beta$-carotene and zeaxanthin amounts were analyzed with an isocratic solvent system ( $90 \%$ methanol:10\% acetonitrile) at $37^{\circ} \mathrm{C}$ for $20 \mathrm{~min}$ and flow rate of $1 \mathrm{~mL} / \mathrm{min}$ at a pressure of 78 bar. Standards for carotenoids ( $\beta$-carotene and zeaxanthin) were obtained from Yuanye Biotech Co., Ltd (Shanghai, China) and dissolved in mobile phase to generate standard curves. Their quantities were performed at wavelengths of $450 \mathrm{~nm}$ with diode array detector (DAD) detector. Pigments were extracted from the $1 \mathrm{~mL}$ culture biomass using $1 \mathrm{~mL}$ of $80 \%(\mathrm{~V} / \mathrm{V})$ acetone, and placed at minus 20 degrees overnight. Before HPLC analysis, clarified samples were filtered with $0.22 \mu \mathrm{m}$ filter into amber vials.

\section{Statistical analysis}

In present study, differences of related gene expression between wild-type (WT) and mutant strain were statistically analyzed using one-way analysis of variance. The statistical significance of differences was determined using t-test and accepted when $P$ value was less than 0.05 . Data were plotted using GraphPad Prism software version 8.0 (GraphPad Software, San Diego, USA).

\section{Results}

\section{sgRNAs cleavage efficacy assay}

Using primers of Dschyb (named as CHY-F and CHYR), 1643 bp sgRNA-targeted fragments were amplified by PCR with WT D. salina genomes. After cleavage efficacy testing of three Cas9 RNP complexes, the results demonstrated that sgRNA1-Cas9 and sgRNA2-Cas9 complexes showed a 100\% cleavage efficiency and yielded a band of expected size. As shown in Fig. 2, the former complex cleaved the target DNA fragment into a $646 \mathrm{bp}$ and a $997 \mathrm{bp}$ lane (Fig. 2 a1), while the latter complex cleaved the target template into a 1057 bp and a 586 bp lane (Fig. 2 a2). But the third complex (sgRNA3-Cas9) failed to cleave the target fragment which offers the third sgRNA is inactive (Fig. 2 a3). When using sgRNA and Cas9 protein alone, it was found that neither sgRNA nor Cas9 protein had cleavage activity to the target fragment. The complex becomes cleavage active only after they bound to each other. The reason mainly results from the different efficiency to CG content, presence of a guanine proximal to the PAM site, and the secondary structure of RNA fold (Jiang et al. 2014).

\section{D. salina transformation and identification of mutants}

According to sgRNA preferred principle, three vectors were successfully constructed with conserved domains of Dschyb gene and confirmed by sequencing (Fig. 3). Based on test results, the effective pKSE401-sgRNA 1 and pKSE401-sgRNA 2 plasmids were used to transform the D. salina cells. Meanwhile, to increase the editing rate, the mixture of pKSE401-sgRNA 1 and pKSE401-sgRNA 2 has been used to transformed the $D$. salina cells. After transformation, six colonies were randomly selected and the Dschyb genes of each sample were amplified by colony PCR. As shown in Fig. 4, PCR products of three mutant strains showed a fragment of about $1 \mathrm{~kb}$ in length (Fig. 4, lane T2-4) which shorter than that of WT D. salina (Fig. 4, lane W, $1.6 \mathrm{~kb}$ ). After gene sequencing, PCR products displayed overlapped peaks in the sequencing chromatography. The WT line and three isolates without target bands were picked for further analysis.

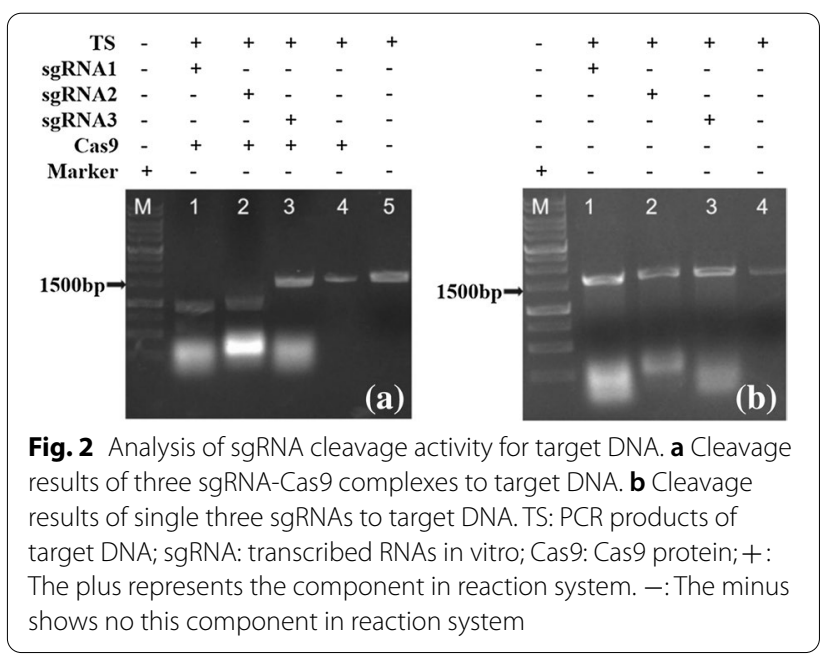




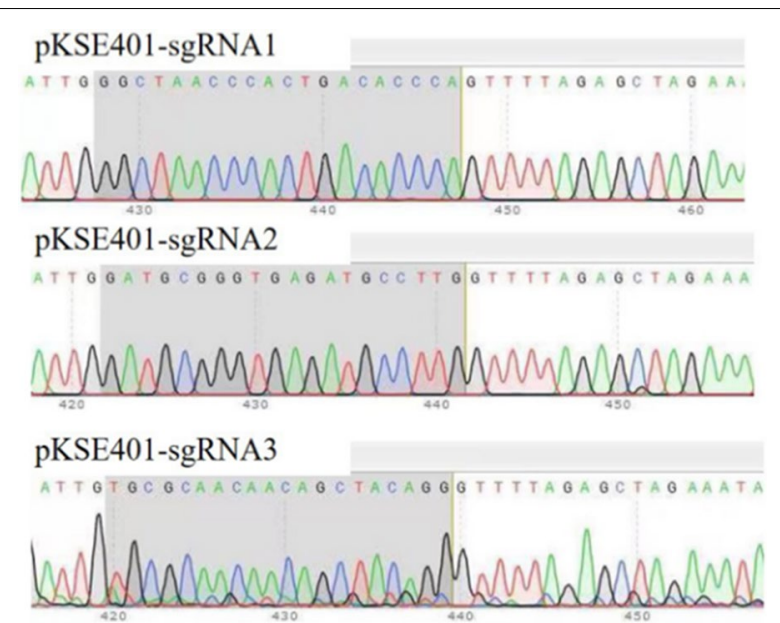

Fig. 3 Sequencing identification of three sgRNA sequences (Gray parts represent the sgRNA base sequences)

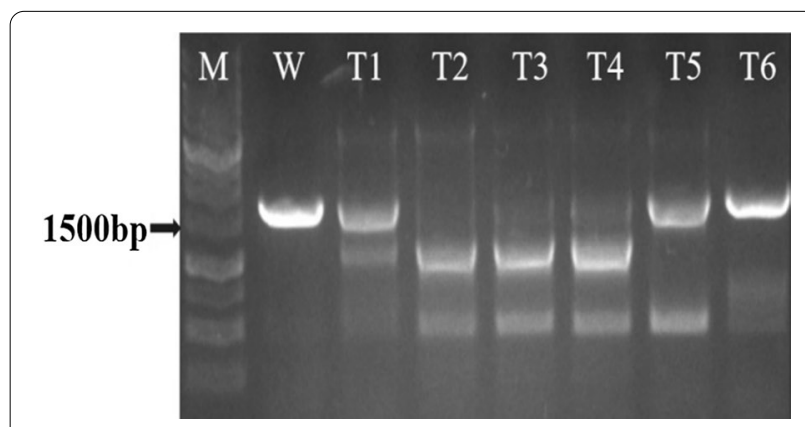

Fig. 4 The results for single algae colony PCR. W: Wild type D. salina strain; T1-6: Transformed D. salina lines

\section{Expression of Dschyb gene in mutants}

Through RT-qPCR analysis, relative expression levels of Dschyb mRNA in mutants were compared with those of WT. The results showed that, compared with the WT D. salina, the Dschyb mRNA levels in T2, T3 and $\mathrm{T} 4$ lines were reduced to $58 \%, 92.5 \%$, and $56.5 \%$, respectively (Fig. 5). In view of this, the expression of the edited Dschyb gene was significantly reduced in mutants. Unfortunately, none of the phenotype showed the complete silencing of Dschyb gene in $D$. salina. Under the light exposure, transcriptional level of Dschyb was up-regulated at $24 \mathrm{~h}$ and reached the highest level at $48 \mathrm{~h}(P<0.01)$ in the WT cells. After constant exposure to strong light conditions, Dschyb mRNA of T3 and T4 lines reached the highest level at $24 \mathrm{~h}$, while T2 was noted the highest level at $48 \mathrm{~h}$. Nevertheless, the levels of Dschyb mRNA of mutant showed significantly decrease than that of WT cells after the high light stress.

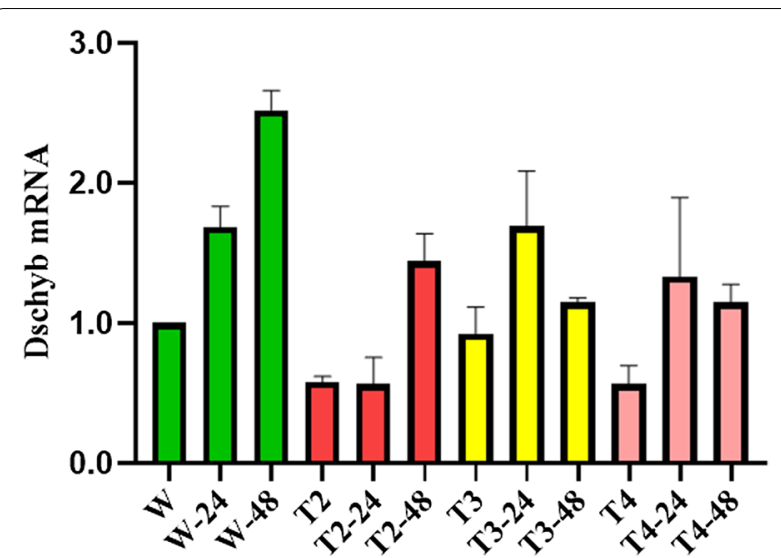

Fig. 5 Relative expression level of Dschyb gene at different times after exposure to high intensity LED light (Values represented as mean $\pm S D(n=3))$. W, W-24, W-48: The mRNA expression levels of Dschyb in WT strain which exposure to high light for $0 \mathrm{~h}, 24 \mathrm{~h}$, and 48 h, respectively; T, T-24, T-48: The expression level of Dschyb in mutant which exposure to high light for $0 \mathrm{~h}, 24 \mathrm{~h}$, and $48 \mathrm{~h}$, respectively

\section{Determination of carotenoid profile in mutants}

Before HPLC analysis, the various parameters were determined, including elution temperature, and mobile phase. Because $D$. salina sample has the largest peak area at $35^{\circ} \mathrm{C}, 35^{\circ} \mathrm{C}$ was used as the most suitable temperature for elution (Fig. 6b). After DAD monitoring at $450 \mathrm{~nm}$, zeaxanthin and $\beta$-carotene profile showed two detectable peaks at 4, 12 min separately (Fig. 6a-c). Based on calibration curves of respective standards (Fig. 6d, e), the carotenoid content of $D$. salina was calculated refer to the experimental section. Through HPLC analysis, the total carotenoids content of three mutants were significantly different from those of WT strains (Fig. 7a). Under the $24 \mathrm{~h}$ light stress, both WT and mutant lines showed the accumulation of $\beta$-carotenoids. Compared with other lines, T3 line showed the maximum accumulation of $\beta$-carotenoids, up to $1.4 \mu \mathrm{g} / \mathrm{mL}$. At the same time, there were significant changes in the level of downstream zeaxanthin (Fig. 7b). The amount of zeaxanthin in WT line was already significantly decreased after high light treatment for $24 \mathrm{~h}$. Only T2 lines rose slightly, the other two mutant lines were down. All these results demonstrated that Dschyb genes were successfully knocked-out and the gene was phenotypically silenced.

\section{Discussion}

Although $D$. salina is a promising host for production of foreign proteins, it still faces many challenges in practical application, including the unclear genome background, unavailability of effective molecular tools, the low or 

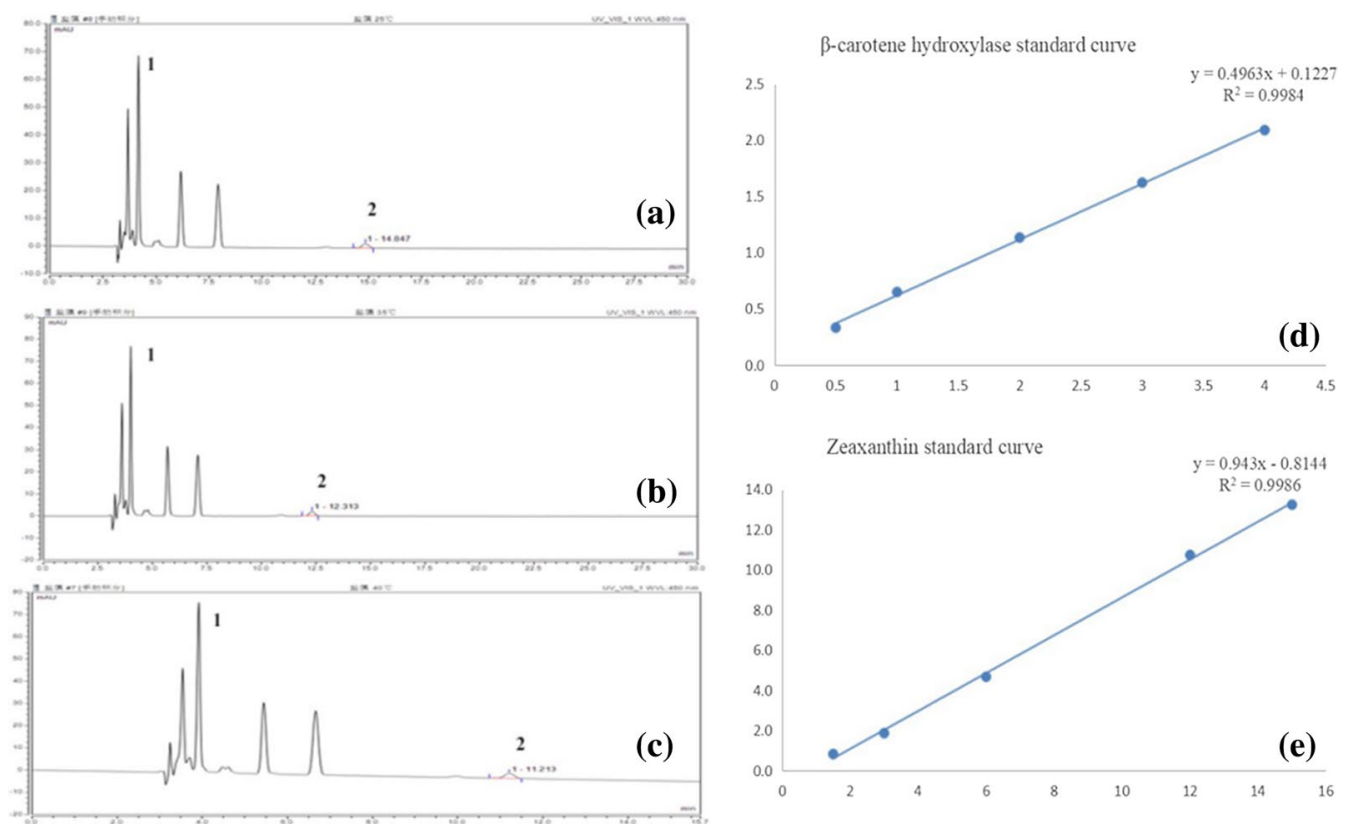

Fig. $6 \mathrm{HPLC}$ with diode-array detection and retention times of D. salina extracts at different temperatures. a HPLC chromatograms of WT D. salina extracts at $25^{\circ} \mathrm{C}$ (Peak 1: zeaxanthin; Peak 2: $\beta$-carotene). b HPLC chromatograms of WT D. salina extracts at $35^{\circ} \mathrm{C}$. $\mathbf{c ~ H P L C ~ c h r o m a t o g r a m s ~ o f ~ W T ~ D . ~}$ salina extracts at $40^{\circ} \mathrm{C}$. $\mathbf{d}$ Standard curve of $\beta$-carotene. e Standard curve of zeaxanthin
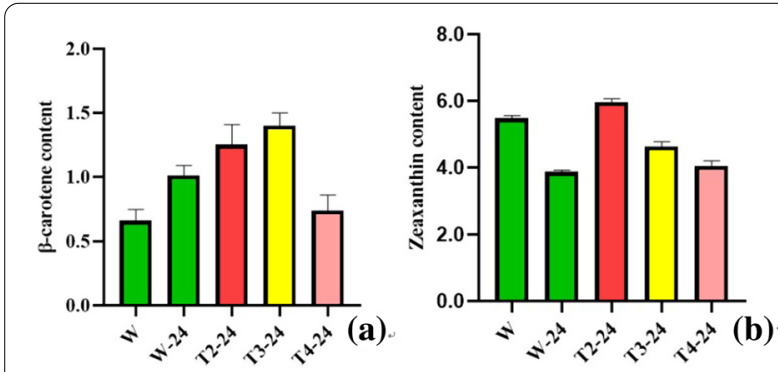

Fig.7 Content of $\beta$-carotene and zeaxanthin in D. salina after $24 \mathrm{~h}$ high light treatment (Values represented as mean $\pm S D(n=3))$. a The $\beta$-carotene content of WT strain and mutants after $24 \mathrm{~h}$ high light treatment. $\mathbf{b}$ The zeaxanthin content of WT strain and mutants after $24 \mathrm{~h}$ high light treatment

inconsistent expression of recombinant proteins, and so on (Liang et al. 2020). In our previous works, the expression of various exogenous genes in D. salina cells was transient, like the human canstatin, and viral envelope proteins (Zhang et al. 2018). To overcome these obstacles of $D$. salina, the emergence of CRISPR/Cas system offers an excellent integration point and a robust and precise genome editing tool for development of $D$. salina system. Through non-homologous end joining and homologues directed repair, CRISPR/Cas9 system provided a more direct route for targeted mutagenesis, causing a ablation or insertion of specific genomic sequences on a single step. Moreover, it has advantages of easy design, simplicity, specificity, and capability of multiplex genome editing. With the completion of chloroplast genome sequencing in $D$. salina, the development of chloroplast expression system will become an attractive research direction (https://www.ncbi.nlm.nih.gov/nuccore/ GQ250046.1). Furthermore, using CRISPR technology to establish the nucleo-plasmic co-expression system of $D$. salina will become a more promising research direction, aiming to realize the high efficient production of exogenous genes.

Compared with the traditional transformation, RNP complex including preassembled Cas9 protein and sgRNA have enabled efficient genome editing in various hosts, such as animal, plants, human cells, and microalgae (DiNapoli et al. 2020; Xing et al. 2014; Kim et al. 2014; Liang et al. 2019). Owing to obviates the need for codon optimization or specific promoters, RNP delivery can be conveniently and rapidly applied in different species. Moreover, owing the degradation of Cas protein in cells by endogenous proteases, RNPs could reduce the off-target effects and mosaicism with a less cytotoxic in cells (Nomura et al. 2019). Simultaneously, the gene-edited plants and animals could be exempt from genetically modified regulations due to the absence of foreign DNA sequences (Kanchiswamy et al. 2015). Therefore, in order to further improve editing efficiency, our team will attempt to use RNP delivery 
system for gene editing of D. salina in next works. However, the disadvantages of RNP components need to be fully considered before the works, like the short half-life, and difficulty in transformation etc.

In conclusion, this study demonstrated that the specific-mutants of Dschyb have been successfully created with CRISPR/Cas9 system. After gene editing, Dschyb gene was knocked-out that induced a 2.2 fold increasing of $\beta$-carotene contents in mutant strains over than that of WT line. Owing to the first successful gene editing of D. salina, it has a very important practical significance for increasing carotene yield and meeting the realistic industry demand. Furthermore, this study not only provides an approach to overcome the current obstacles of $D$. salina, but also gives a strong tool to facilitates the development and application of D. salina system.

\begin{abstract}
Abbreviations
D. salina: Dunaliella salina; CRISPR: Clustered regularly interspaced short palindromic repeat; PCR: Polymerase chain reaction; HPLC: High-performance liquid chromatography; sgRNA: Single guide RNA; RT-qPCR: Real-time fluorescent quantitative $P C R$; Dschyb: Beta-carotene hydroxylase of $D$. salina; RNP: Ribonucleoprotein; LED: Light emitting diode; DAD: Diode array detector; WT: Wild type.
\end{abstract}

\section{Acknowledgements}

The authors gratefully acknowledge Professor SHI Gongyao of Life Science College of Zhengzhou University for presenting plasmid pKSE401.

\section{Authors' contributions}

LN, SY wrote the manuscript. LN, JX, GF made the table. LN, SY, AF drew the pictures. SY, LN, CL conduct the HPLC analysis. All authors read and approved the manuscript.

\section{Funding}

This study was founded by the National Natural Science Foundation of China (No. U1804112, 31571289), and the Zhongjing Core Scholar's Research Initial Fund of Henan University of Chinese Medicine (No. 00104311-2020-1).

\section{Availability of data and materials}

The data of this article is included within the article. And also, the data and materials can also be requested from the corresponding author and the first author.

\section{Declarations}

Ethics approval and consent to participate

Not applicable.

\section{Consent for publication}

Not applicable.

\section{Competing interests}

The authors declare no conflicts of interest in relation to this research and its publication.

\section{Author details}

${ }^{1}$ School of Basic Medical Sciences, Henan University of Science and Technology, No. 263 Kaiyuan Avenue, Luoyang 471023, Henan, China. ${ }^{2}$ Medical College, Henan University of Chinese Medicine, Zhengzhou 450046, Henan, China. ${ }^{3}$ Academy of Chinese Medicine Sciences, Henan University of Chinese Medicine, Zhengzhou 450046, Henan, China.
Received: 6 March 2021 Accepted: 31 May 2021

Published online: 07 June 2021

\section{References}

Berman J, Zorrilla-López U, Sandmann G, Capell T, Christou P, Zhu C (2017) The silencing of carotenoid $\beta$-hydroxylases by RNA interference in different maize genetic backgrounds increases the $\beta$-carotene content of the endosperm. Int J Mol Sci 18(12):2515

DiNapoli SE, Martinez MR, Gribbin CK, Wrighton PJ, Balgobin CA, Nelson I, Leonard A, Maskin CR, Shwartz A, Quenzer ED, Mailhiot D, Kao C, McConnell SC, de Jong JLO, Goessling W, Houvras Y (2020) Synthetic CRISPR/ Cas9 reagents facilitate genome editing and homology directed repair. Nucleic Acids Res 48(7):e38

Fellmann C, Gowen BG, Lin PC, Doudna JA, Corn JE (2017) Cornerstones of CRISPR-Cas in drug discovery and therapy. Nat Rev Drug Discov 16(2):89-100

Feng S, Hu L, Zhang Q, Zhang F, Du J, Liang G, Li A, Song G, Liu Y (2020) CRISPR/Cas technology promotes the various application of Dunaliella salina system. Appl Microbiol Biotechnol 104(20):8621-8630

Jiang W, Brueggeman AJ, Horken KM, Plucinak TM, Weeks DP (2014) Successful transient expression of Cas9 and single guide RNA genes in Chlamydomonas reinhardtii. Eukaryot Cell 13(11):1465-1469

Kanchiswamy CN, Malnoy M, Velasco R, Kim JS, Viola R (2015) Non-GMO genetically edited crop plants. Trends Biotechnol 33(9):489-491

Khadempar S, Familghadakchi S, Motlagh RA, Farahani N, Dashtiahangar M, Rezaei H, Gheibi Hayat SM (2019) CRISPR-Cas9 in genome editing: its function and medical applications. J Cell Physiol 234(5):5751-5761

Kim SH, Ahn YO, Ahn MJ, Lee HS, Kwak SS (2012) Down-regulation of $\beta$-carotene hydroxylase increases $\beta$-carotene and total carotenoids enhancing salt stress tolerance in transgenic cultured cells of sweetpotato. Phytochemistry 74:69-78

Kim S, Kim D, Cho SW, Kim J, Kim JS (2014) Highly efficient RNA-guided genome editing in human cells via delivery of purified Cas9 ribonucleoproteins. Genome Res 24(6):1012-1019

Lamers PP, Janssen M, De Vos RCH, Bino RJ, Wijffels RH (2008) Exploring and exploiting carotenoid accumulation in Dunaliella salina for cell-factory applications. Trends Biotechnol 26(11):631-638

Liang MH, Wang L, Wang Q, Zhu J, Jiang JG (2019) High-value bioproducts from microalgae: strategies and progress. Crit Rev Food Sci Nutr 59(15):2423-2441

Liang ZC, Liang MH, Jiang JG (2020) Transgenic microalgae as bioreactors. Crit Rev Food Sci Nutr 60(19):3195-3213

Nomura T, Inoue K, Uehara-Yamaguchi Y, Yamada K, Iwata O, Suzuki K, Mochida K (2019) Highly efficient transgene-free targeted mutagenesis and single-stranded oligodeoxynucleotide-mediated precise knock-in in the industrial microalga Euglena gracilis using Cas9 ribonucleoproteins. Plant Biotechnol 17(11):2032-2034

Nymark M, Sharma AK, Sparstad T, Bones AM, Winge P (2016) A CRISPR/Cas9 system adapted for gene editing in marine algae. Sci Rep 6:24951

Saha SK, Kazipet N, Murray P (2018) The carotenogenic Dunaliella salina CCAP 19/20 produces enhanced levels of carotenoid under specific nutrients limitation. Biomed Res Int. https://doi.org/10.1155/2018/7532897

Sternberg SH, Redding S, Jinek M, Greene EC, Doudna JA (2014) DNA interrogation by the CRISPR RNA-guided endonuclease Cas9. Nature 507(490):62-67

Vecchione S, Fritz G (2019) CRIMoClo plasmids for modular assembly and orthogonal chromosomal integration of synthetic circuits in Escherichia coli. J Bio Eng 13:92

Wichuk K, Brynjólfsson S, Fu W (2014) Biotechnological production of value-added carotenoids from microalgae: emerging technology and prospects. Bioengineered 5(3):204-208

Xi Y, Wang J, Xue S, Chi Z (2020) $\beta$-Carotene production from Dunaliella salina cultivated with bicarbonate as carbon source. J Microbiol Biotechnol 30(6):868-877

Xing HL, Dong L, Wang ZP, Zhang HY, Han CY, Liu B, Wang XC, Chen QJ (2014) A CRISPR/Cas9 toolkit for multiplex genome editing in plants. BMC Plant Bio 14:327 
Xu Y, Harvey PJ (2019) Red light control of $\beta$-carotene isomerisation to 9-cis $\beta$-carotene and carotenoid accumulation in Dunaliella salina. Antioxidants (basel) 8(5):148

Xu Y, Ibrahim IM, Wosu Cl, Ben-Amotz A, Harvey PJ (2018) Potential of new isolates of Dunaliella salina for natural $\beta$-carotene production. Biology (basel) 7(1):E4

Yang H, Wu JJ, Tang T, Liu KD, Dai C (2017) CRISPR/Cas9-mediated genome editing efficiently creates specific mutations at multiple loci using one sgRNA in Brassica napus. Sci Rep 7:7489
Zhang Z, He P, Zhou Y, Xie X, Feng S, Sun C (2018) Anti-HBV effect of interferon-thymosin a1 recombinant proteins in transgenic Dunaliella salina in vitro and in vivo. Exp Ther Med 16(2):517-522

\section{Publisher's Note}

Springer Nature remains neutral with regard to jurisdictional claims in published maps and institutional affiliations.
Submit your manuscript to a SpringerOpen ${ }^{\circ}$ journal and benefit from:

- Convenient online submission

- Rigorous peer review

- Open access: articles freely available online

- High visibility within the field

Retaining the copyright to your article

Submit your next manuscript at $\boldsymbol{\nabla}$ springeropen.com 